Bird Conservation International (2021) 31:268-285. C The Author(s), 2020. Published by Cambridge University Press on behalf of BirdLife International. This is an Open Access article, distributed under the terms of the Creative Commons Attribution-NonCommercial- ShareAlike licence (http://creativecommons.org/licenses/by-nc-sa/4.0/), which permits non-commercial reuse, distribution, and reproduction in any medium, provided the same Creative Commons licence is included and the original work is properly cited. The written permission of Cambridge University Press must be obtained for commercial re-use.

doi:10.1017/S0959270920000349

\title{
Expert knowledge assessment of threats and conservation strategies for breeding Hen Harrier and Short-eared Owl across Europe
}

\author{
DARÍO FERNÁNDEZ-BELLON ${ }^{1,2,3^{*}}$ (D), JOHN LUSBY ${ }^{4}$, JULES BOS ${ }^{5}$, \\ TONIO SCHAUB ${ }^{6}$, ALAN MCCARTHY $^{1}$, ANTHONY CARAVAGGI $^{1,7}$, \\ SANDRA IRWIN ${ }^{1}$ and JOHN O'HALLORAN ${ }^{1}$ \\ ${ }^{1}$ School of Biological, Earth and Environmental Science (BEES), University College Cork, \\ Distillery Fields, North Mall, Cork, Ireland. \\ ${ }^{2}$ MKO Research, McCarthy Keville O'Sullivan, Tuam Road, Galway, Ireland. \\ ${ }^{3}$ Environmental Research Institute, University College Cork, Lee Road, Cork, Ireland. \\ ${ }^{4}$ BirdWatch Ireland, Kilcoole, County Wicklow, Ireland. \\ ${ }^{5}$ BirdLife Netherlands (Vogelbescherming Nederland), P.O. Box 925, NL-370o AX Zeist, The \\ Netherlands. \\ ${ }^{6}$ Dutch Montagu's Harrier Foundation, Postbus 46, NL-9679 ZG Scheemda, The Netherlands. \\ ${ }^{7}$ University of South Wales, 9 Graig Fach, Pontypridd CF 37 4BB, UK. \\ *Author for correspondence; email: d.fernandezbellon@umail.ucc.ie
}

(Received 21 August 2019; revision accepted 30 March 2020)

\section{Summary}

Hen Harrier Circus cyaneus and Short-eared Owl Asio flammeus are open-country birds of prey with overlapping distributions. Although both species face similar conservation threats across their ranges, work to date has largely been undertaken at a national scale with few attempts to collate and assess factors relevant to their conservation at an international scale. Here we use an expert knowledge approach to evaluate the impact of conservation threats and the effectiveness of conservation strategies for each species across Europe. We report results of responses to a questionnaire from 23 Hen Harrier experts from nine countries and 12 Short-eared Owl experts from six countries. The majority of responses for both species reported declines in breeding numbers. The perceived impact of threats was broadly similar for both species: ecological factors (predation, extreme weather and prey availability), changes in land use (habitat loss and agricultural intensification) and indirect persecution (accidental nest destruction) were considered to be the greatest threats to breeding Hen Harrier and Short-eared Owl. Short-eared Owl experts also highlighted lack of knowledge and difficulties associated with monitoring as a major conservation challenge. Despite broad-scale similarities, geographical variation was also apparent in the perceived importance of conservation threats, with some threats (such as direct persecution, large-scale afforestation or habitat degradation) requiring country-specific actions. Implementation of different conservation strategies also varied between countries, with the designation of protected areas reported as the most widespread conservation strategy adopted, followed by species and habitat management. However, protected areas (including species-specific protected areas) were perceived to be less effective than active management of species and habitats. These findings highlight the overlap between the conservation requirements of these two species, and the need for collaborative international research and conservation approaches that prioritise pro-active conservation strategies subject to continued assessment and with specific conservation goals.

Keywords: Asio flammeus, Circus cyaneus, conservation effectiveness, expert knowledge, questionnaire 


\section{Introduction}

Hen Harrier Circus cyaneus and Short-eared Owl Asio flammeus are open-country birds of prey with overlapping Palearctic distributions (BirdLife International 2019). Outside of Eurasia, Shorteared Owl populations overlap with Hen Harrier sister species (Circus hudsonius and Circus cinereus) in North and South America (Bierregaard et al. 2019, Del Hoyo et al. 2019). In Europe, both species breed from Spain, Ireland, and the UK in the west, through central Europe and Nordic countries to Eastern Europe and Russia, while migratory movements extend as far as northern Africa (BirdLife International 2019). Both species nest on the ground in a variety of landscapes across Europe, including tundra, upland moors and bogs, agricultural grasslands and crops, or coastal dune habitats (Olsen et al. 2019, Orta et al. 2019). As well as sharing breeding habitats, there are also overlaps between the prey range used by both species. Hen Harriers feed mainly on birds, small mammals and lagomorphs, with the relative importance of different prey groups depending on the habitat, season and region within Europe (Orta et al. 2019). Short-eared Owls have a similar diet, but are more dependent on small mammals, especially voles Microtus spp., that experience important population fluctuations (Olsen et al. 2019). As a result of their broadly similar diets, nesting and foraging habitat requirements, the two species are affected by similar conservation pressures and threats (European Environment Agency 2012, Olsen et al. 2019, Orta et al. 2019). Though previously abundant, both species have suffered declines in recent decades (BirdLife International 2004) and are now listed as Annex I species on the EU Birds Directive (2009/147/EC), as Annex II species on the Bern Convention, and as species of conservation concern at a national level across Europe (in 20 and in 33 countries for Hen Harrier and Short-eared Owl respectively; Staneva and Burfield 2017). Substantial breeding population declines have been reported for Hen Harrier across many European countries (European Environment Agency 2012), while Short-eared Owl breeding population trends are surrounded by uncertainty (BirdLife International 2004) due to fluctuating populations (Calladine et al. 2012) and to difficulties associated with reliably monitoring this species (Calladine et al. 2010). Despite the overlap in ecological patterns and conservation concern for both species across their entire European range, most research and monitoring has focused on populations at a national or regional scale. Furthermore, there is a lack of published research from large parts of their European range and the information that is available is often in the form of grey literature and national survey or monitoring reports. As a result, assessing the conservation status of these species and identifying patterns relevant for their conservation at an international scale remains problematic. The Birds Directive reporting under Article 12 seeks to address this issue by providing an overview of the status and trends of bird populations in member states (European Environment Agency 2012). However, gaps remain in our current knowledge regarding practical conservation approaches for both species.

Expert knowledge approaches can provide a useful tool to improve our understanding of complex conservation problems (Martin et al. 2012). Here we aim to complement existing knowledge on the status and trends of Hen Harrier and Short-eared Owl (e.g. European Environment Agency 2012) with expert perceptions of the relative impact of threats and the effectiveness of different conservation strategies in place for each species across Europe. We used an expert knowledge-based approach in conjunction with the first International Hen Harrier and Short-eared Owl meeting held in the Netherlands in 2019 (Bos et al. 2020) to provide an overview of expert views on (i) conservation threats to Hen Harrier and Short-eared Owl breeding populations across Europe, and (ii) effectiveness of conservation strategies in place for each species in different European countries.

\section{Methods}

We assessed expert knowledge on threats and conservation strategies for Hen Harrier and Shorteared Owl breeding populations across Europe by means of a questionnaire. The aim of the questionnaire was to characterise (i) the study population of each expert, (ii) conservation threats 
to each species and (iii) the effectiveness of any conservation strategies in place (see the online supplementary material for the full questionnaire). To trial the questionnaire, we sent a pilot version to 10 individuals with relevant experience in bird conservation and research. We received six responses which helped improve the format and resolve any technical issues. The final questionnaire was circulated to 60 Hen Harrier and Short-eared Owl experts from 14 countries who had been invited to attend the 2019 International Hen Harrier and Short-eared Owl meeting and to five other experts identified by meeting attendees $(n=65)$. As respondents' experience covered different geographical areas, some of which overlapped or were nested within each other, the unit of study for this research was the questionnaire response (rather than the population covered by each response). Furthermore, questionnaires were perception-based and thus sought to complement, rather than repeat work carried out by Article 12 reporting under the Birds Directive (European Environment Agency 2012).

Respondents were first asked to describe the number of breeding pairs and trend (i.e. increasing, stable, decreasing, unknown) in their area. Experts were then asked to rate the relative impact of conservation threats and the effectiveness of conservation strategies in their study area. A list of threats and strategies was provided based on the IUCN conservation threats and actions classification schemes (IUCN 2012a, 2012b) and Salafsky et al. (2008), adapted to Hen Harrier and Short-eared Owl ecology and conservation (BirdLife International 2019, Olsen et al. 2019, Orta et al. 2019). A total of 23 threats and 14 conservation strategies were included in the questionnaire, grouped into six and four categories, respectively (Table I). Questionnaires included space to list and rate additional threats and strategies not captured by the list provided as well as to provide any additional relevant information. Respondents rated conservation threats on a scale of 1 to 5 , from "lowest or negligible impact" to "highest impact". Respondents assigned a value of 'NA' to threats that they considered not to occur in their study area. Two specific threats (prey availability and extreme weather) were not listed in the original questionnaire but were highlighted in several responses in the sections provided for additional threats. To obtain an accurate representation of the importance of these particular threats, all respondents were contacted again and asked to evaluate these two threats in the same way as in the original questionnaire. Responses on these threats were then incorporated into the analysis. Respondents were asked to similarly rate the effectiveness of conservation strategies on a scale of $I$ to 5 , from "ineffective; breeding success is similar to what would be expected without that strategy" to "very effective; breeding success is optimised under that strategy". Conservation strategies not in place in a respondent's study area were identified as 'NA'.

To calculate the relative impact of conservation threats, all threats not reported in an area (NA) were given a value of $\mathrm{o}$. This avoided overestimating the importance of threats which were reported only in one area (e.g. parasites were only highlighted as an issue in one response, if treating responses from all other questionnaires as NA, the importance of parasites at a European scale would be overestimated). As multiple questionnaires were received for some countries / regions, we first evaluated conservation threats at a national scale by calculating a national mean value for each threat. A European mean value was then calculated from the national means to evaluate the relative importance of conservation threats across Europe. This avoided overestimating the importance of threats from countries with multiple responses. A similar process was followed to evaluate the effectiveness of conservation strategies, but in this case, NA values were omitted from calculations. The reason for this was that threats could be treated as a continuous variable, from not occurring (O), to having a low impact ( 1 ), to having a high impact (5), whereas conservation strategies could not be treated as continuous (they are in place (yes/no), once in place they can then be considered to be ineffective (I) to very effective (5).

Some of the questionnaire responses covered relatively small numbers of breeding pairs $(<10)$. As small populations are known to have increased vulnerability to extinction through stochastic events (Melbourne and Hastings 2008), we assessed whether the perceived importance of threats was consistent across responses covering different numbers of breeding pairs. For each questionnaire response, we calculated the mean value of each threat category (six categories consisting of 3-6 threats each; Table 1). We then fitted a linear model to highlight any trends between the 
Table 1. Summary of conservation threats and strategies for Hen Harrier and Short-eared Owl assessed by European experts through the questionnaire

\begin{tabular}{|c|c|c|c|}
\hline \multicolumn{2}{|c|}{ Conservation threats } & \multicolumn{2}{|c|}{ Conservation strategies } \\
\hline Category & Threat & Category & Strategy \\
\hline \multirow[t]{4}{*}{ Ecological } & Predation & Protection & Protected area \\
\hline & Extreme weather & & Species-specific protected area (SPA) \\
\hline & Prey availability & Species management & Nest protection (from direct or indirect persecution) \\
\hline & Parasites & & Supplementary feeding \\
\hline \multirow[t]{3}{*}{ Direct persecution } & Shooting & & Brood management \\
\hline & Poisoning & & Predator control (nest scale) \\
\hline & Nest destruction & & Predator control (landscape scale) \\
\hline \multirow[t]{2}{*}{ Indirect persecution } & Secondary poisoning & Habitat management & Improvement of nesting habitat \\
\hline & Accidental nest destruction (e.g. by crop harvesting) & & Improvement of foraging habitat \\
\hline \multirow[t]{4}{*}{ Collision } & Wind turbines & & Improvement of linear features \\
\hline & Power lines & & Improvement of grazing regimes \\
\hline & Cars / trains & Policy and legislation & Regulation of afforestation and forestry activities \\
\hline & Fences & & Regulation of recreation \\
\hline \multirow[t]{4}{*}{ Disturbance } & Forestry & & Rodenticide use regulation \\
\hline & Agriculture & & \\
\hline & Burning & & \\
\hline & Recreational activities & & \\
\hline \multirow[t]{6}{*}{ Anthropogenic habitat change } & Habitat loss & & \\
\hline & Afforestation & & \\
\hline & Agricultural intensification & & \\
\hline & Grazing regimes & & \\
\hline & Recreation infrastructures & & \\
\hline & Developments (e.g. renewable energy) & & \\
\hline
\end{tabular}

Agricultural intensification

Recreation infrastructures

Developments (e.g. renewable energy) 
perceived importance of each threat category and the number of breeding pairs covered by the questionnaire responses. To maximise sample size, and as the two species share ecological traits and conservation threats, data for both species were pooled for this analysis. In some cases, different questionnaire responses corresponded to overlapping or nested geographical areas. To avoid pseudo-replication, we also performed this analysis excluding multiple responses from the same area. Specifically, for areas that were covered by more than one response, we only used data from the response covering the largest number of pairs to avoid pseudo-replication. However, as results were the same for both analyses (Figure 4 and Figure $\mathrm{S}_{1}$ ), we present the data including all questionnaire responses.

\section{Results}

We received 36 responses from experts in 1o different countries across the European range of both species. Geographical coverage was best in central and western Europe, with gaps in Nordic and eastern European countries. Expert respondents were from a range of backgrounds including conservation organisations, research centres, government bodies, survey and monitoring programmes, and consultancy and environmental impact studies. One response on Hen Harrier referred to a wintering population which was therefore excluded from further analyses. The remaining questionnaires included 23 responses on breeding Hen Harrier from nine countries and 12 responses on breeding Short-eared Owl from six countries. Seventy percent of Hen Harrier and $58 \%$ of Short-eared Owl responses reported declining trends (Hen Harrier: 4 stable, 16 declining, 2 extinct, I unknown; Short-eared Owl: I increasing, 2 stable, 7 declining, I extinct, $I$ unknown). Figure $I$ summarises the number of pairs, trends and countries covered by the questionnaire responses.

The conservation threats with the greatest perceived impact $(\geq 2.4)$ for breeding Hen Harrier populations in Europe were agricultural intensification, habitat loss, accidental nest destruction and prey availability (Figure 2). However, the impact of these threats was variable across Europe (large SD values in Figure 2 and variation in Figure 3). For Short-eared Owl breeding populations, the most important threats $(\geq 2.4)$ were prey availability, extreme weather, habitat loss, agricultural intensification, and predation (Figure 2), with similar geographical variability (Figure 3). Overall, the patterns of the different threats were broadly similar for both species: the mean difference between both species for each threat was $0.46(\mathrm{SD}=0.35)$, with most threats showing a difference of less than 0.7. Short-eared Owls were perceived as more vulnerable to changes in prey availability, car and train collisions, and extreme weather events (difference with Hen Harrier mean value of 1.5, 1 and 0.8 respectively). Disturbance from forestry activities was considered more important for Hen Harrier (difference of I with Short-eared Owl mean value). Within countries with multiple expert responses, scoring of threats was generally most similar for those threats perceived as most important (indicated by SD values in Tables $\mathrm{S}_{2}$ and $\mathrm{S}_{3}$ ).

Threat categories (i.e. ecological, direct persecution, indirect persecution, collision, disturbance, anthropogenic habitat change) had different impacts depending on the number of breeding pairs (Figure 4). All threat categories had variable impact at small population sizes, but for large populations ecological factors, direct persecution and anthropogenic habitat change had a larger impact. On the other hand, the perceived impact of indirect persecution declined for larger populations, while the perceived impact of collisions and disturbance appeared to be independent of population size.

The most frequently applied conservation strategies for breeding Hen Harrier and Short-eared Owl across European countries covered by questionnaires were the designation of protected areas, followed by species and habitat management (Table 2). Overall, ratings of the effectiveness of conservation strategies were more variable (average $\mathrm{SD}=1.32$, Figure 5) than those of conservation threats (average $\mathrm{SD}=0.76$, Figure 2). The conservation strategies perceived to be most effective were those targeting the improvement of nesting and foraging habitat and those related to control of predation (Figure 5). Protected areas (including those specifically designated for Hen 


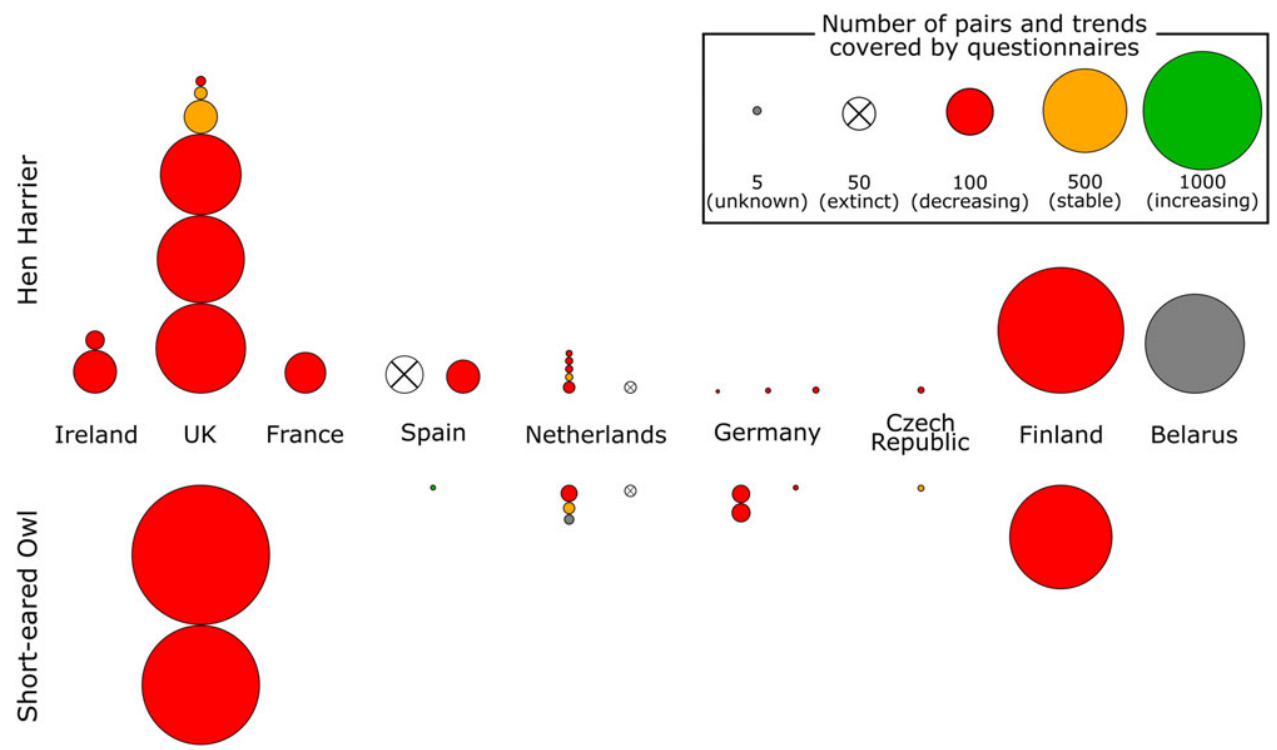

Figure 1. Geographic distribution of responses to Hen Harrier (top) and Short-eared Owl (bottom) questionnaires. Circle sizes indicate the number of pairs covered by each questionnaire (range: $1-1,375$ pairs), circle colour indicates the trend reported by each questionnaire. Where two or more questionnaires covered overlapping or nested geographical areas, these are vertically aligned (e.g. six responses on Hen Harrier from the UK covered the entire UK and subpopulations; as a comparison, the two responses from Spain covered separate areas and so are horizontally aligned). Where populations are marked as extinct, the population size shown corresponds to the population size to years prior to extinction.

Harrier or Short-eared Owl) were considered to have low effectiveness, despite being one of the most widely applied conservation strategies in Europe (Table 2). The effectiveness of conservation strategies was perceived to be roughly similar for both species, with a mean absolute difference of $0.87(\mathrm{SD}=0.53)$ between species.

\section{Discussion}

Our expert knowledge approach resulted in broad geographical coverage of European Hen Harrier and Short-eared Owl breeding populations (Figure 3). Responses highlighted a general decline in breeding numbers of both species across Europe, in line with reported national trends (European Environment Agency 2012, Staneva and Burfield 2017). It is worth noting that we obtained considerably more responses for Hen Harrier $(n=23)$ than Short-eared Owl $(n=12)$ and that some areas were covered by multiple questionnaire responses (notably the UK and the Netherlands) while other areas had poor coverage (Nordic and eastern European countries). These patterns in numbers of responses partly reflect the disparity in research and conservation efforts for both species throughout Europe and also the strong spatio-temporal fluctuations of Short-eared Owl breeding populations (Mikkola 2010). Poor coverage in eastern Europe and Russia also reflects a broader concern about ecological knowledge transfer and access to literature between east and west (Henry and Douhovnikoff 2008, Smith et al. 2014, Doi and Takahara 2016). Despite these gaps, questionnaire responses provided a good representation of the conservation threats and strategies of both species' populations across central and western Europe. 


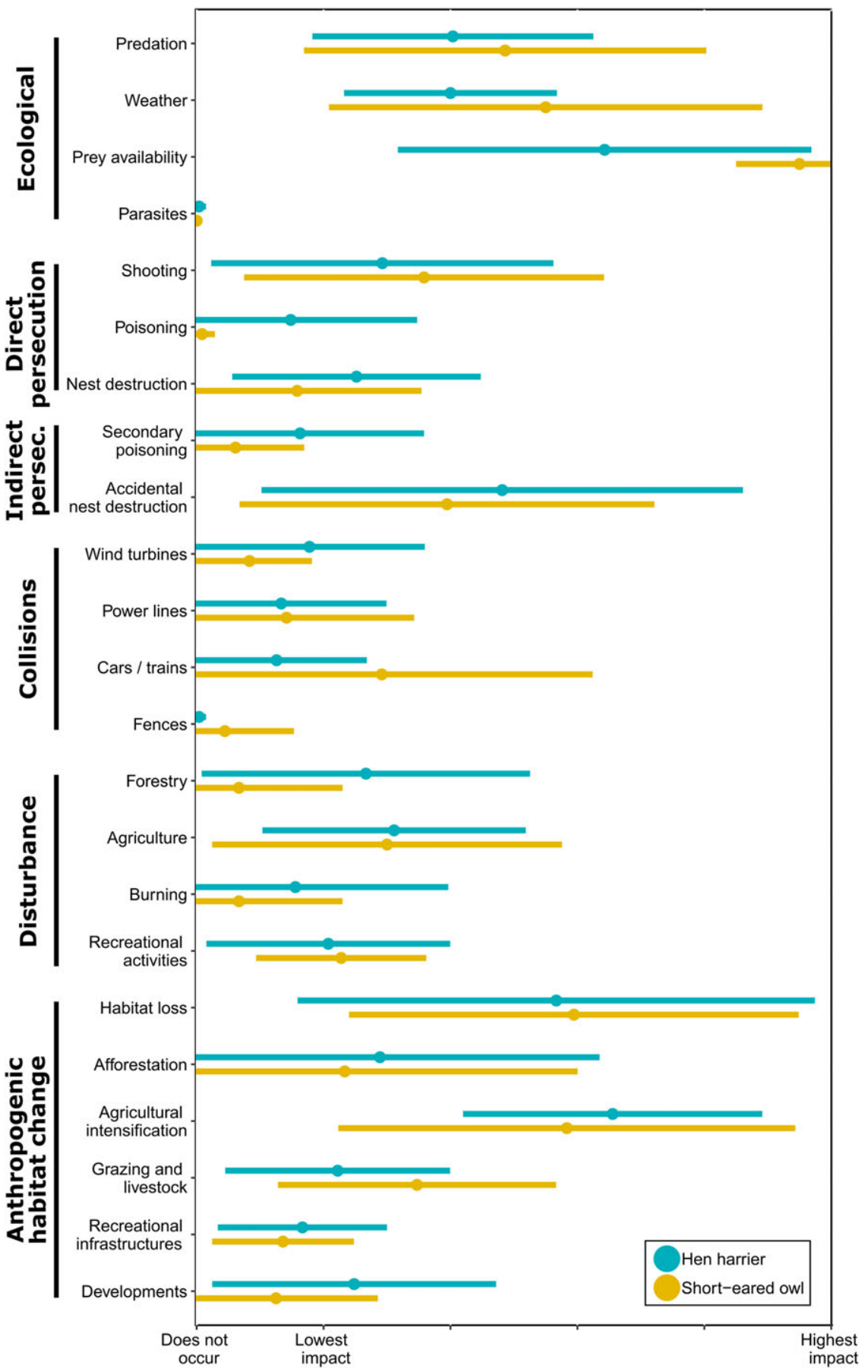

Figure 2. Perceived impact of conservation threats to breeding Hen Harrier and Short-eared Owl assessed by European experts through questionnaires $(n=23$ responses from nine countries for Hen Harrier; $n=12$ responses from six countries for Short-eared Owl). Dots indicate mean values for each threat across all countries, lines indicate standard deviation. See Table $\mathrm{S}_{1}$ for mean and standard deviation values. 


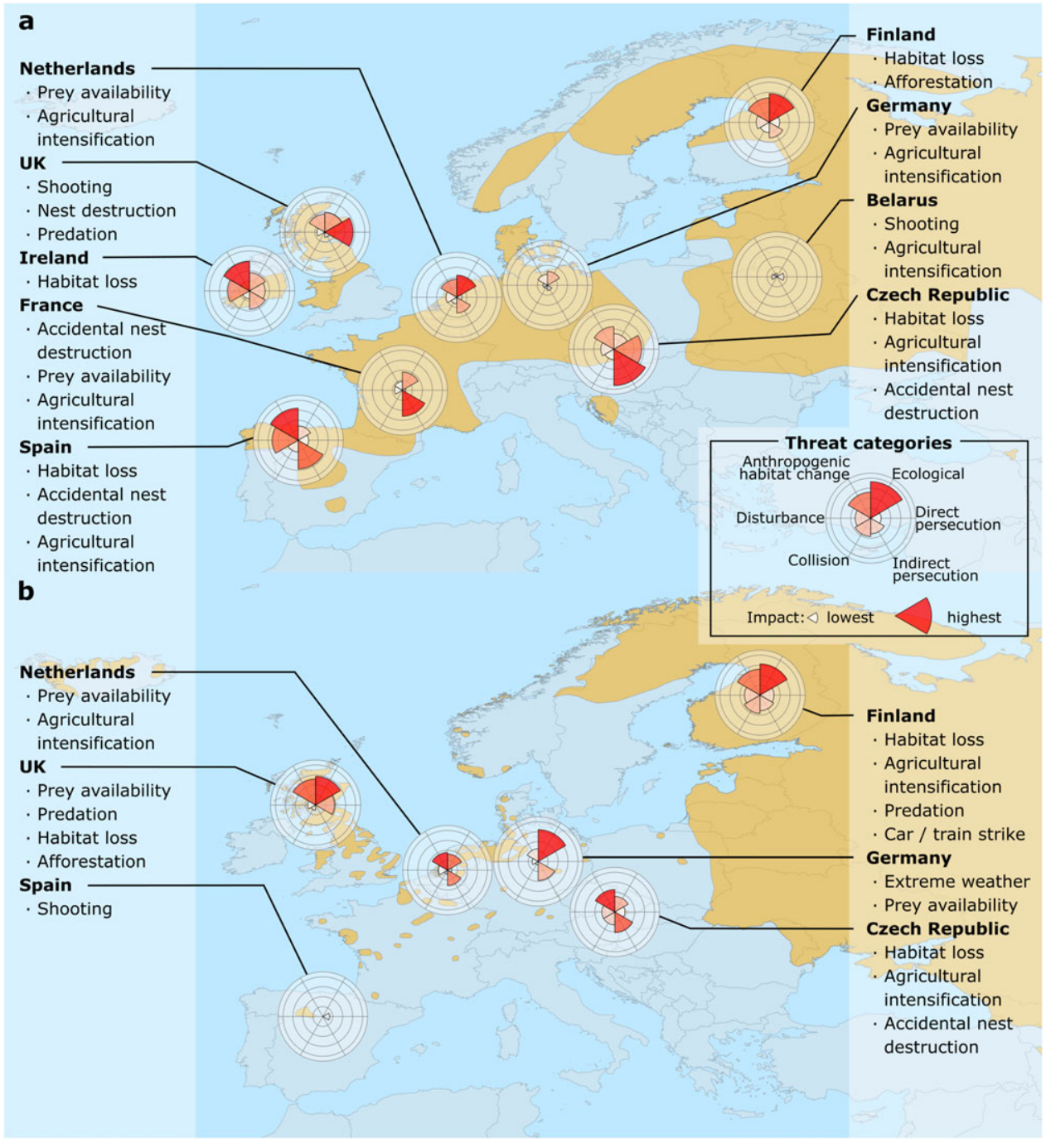

Figure 3. Conservation threats to breeding Hen Harrier (a) and Short-eared Owl (b) assessed by European experts through questionnaires. Circle section size and colours indicate the estimated impact of the different threat categories (see legend). Lists indicate specific threats perceived to be most important in each country (i.e. in the upper quartile based on threat scores for each country). See Tables $\mathrm{S}_{2}$ and $\mathrm{S}_{3}$ for full list of threats and perceived impact values in each country. Breeding distribution maps based on BirdLife International and HBW (2018).

The perceived impact of threats to Hen Harrier and Short-eared Owl showed some interesting patterns. Firstly, the impact of the different threats was broadly similar for both species, underlining the overlap in ecological requirements and conservation concerns for these species. Where threat impacts differed, this could be linked to ecological differences. For example, due to their strong reliance on small mammals, Short-eared Owl populations are more vulnerable to natural fluctuations in prey availability (Korpimaki and Norrdahl 1991), and their partly nocturnal foraging behaviour makes them more vulnerable to collisions with cars and trains (Village 1987, 


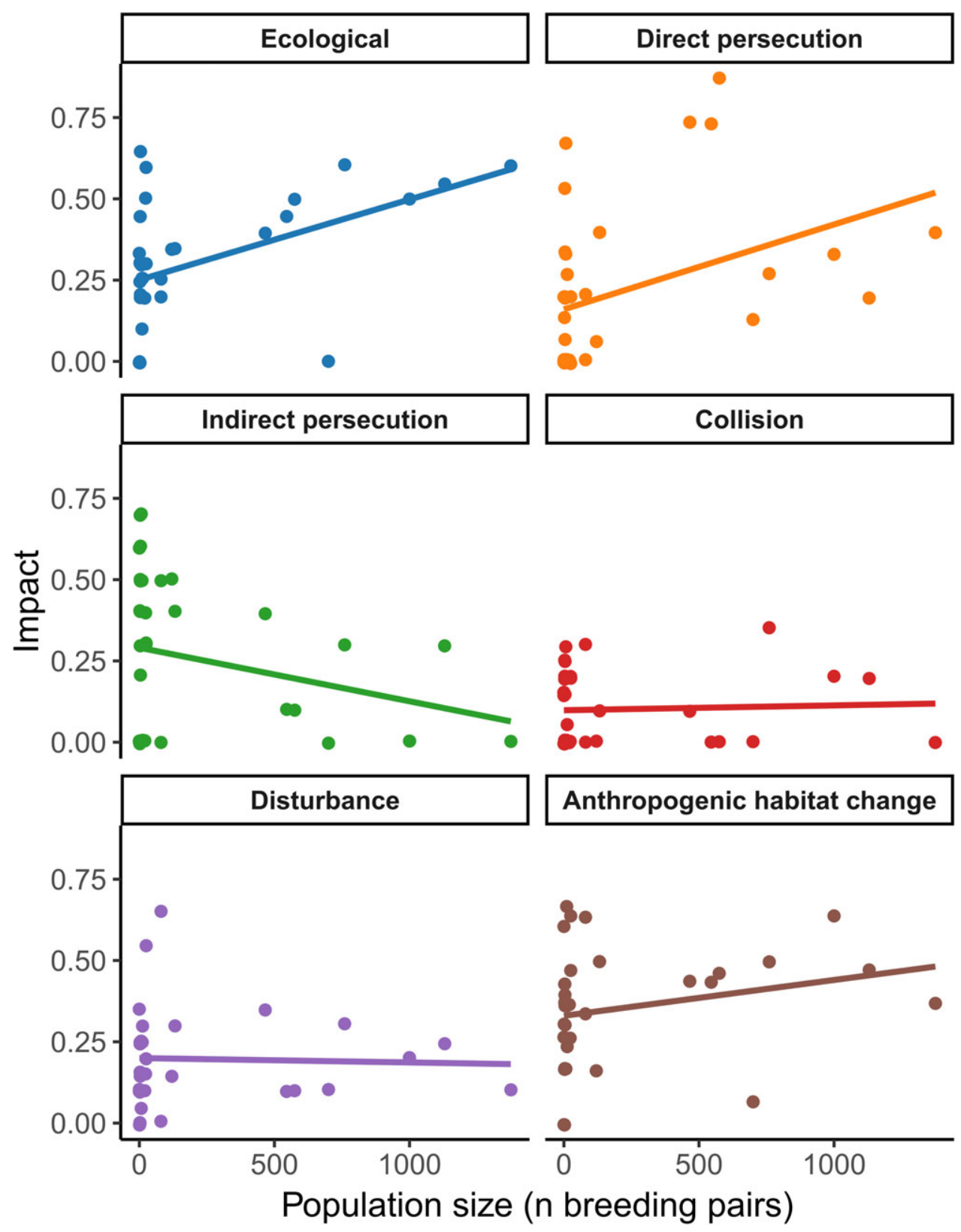

Figure 4. Perceived impact of different threats to breeding Hen Harrier and Short-eared Owl populations reported by European experts in relation to number of breeding pairs covered by each questionnaire (data for Hen Harrier, $\mathrm{n}=23$, and Short-eared Owl, $\mathrm{n}=12$, are pooled).

Calladine et al. 2012). Secondly, our results highlighted the importance of ecological factors (predation, extreme weather, and prey availability), anthropogenic habitat change (habitat loss and agricultural intensification) and indirect persecution (accidental nest destruction) for both species. Human activities influence not only the latter two (anthropogenic habitat change and 
Table 2. Conservation strategies reported for breeding Hen Harrier (green / dark dots) and Short-eared Owl (orange / light dots) by European experts through questionnaires. Note that this table reflects conservation strategies from respondents' study areas, and are therefore not necessarily representative of conservation strategies at a national scale (e.g. a respondents' study may be outside protected areas, and therefore this strategy was not marked in their response; conversely, respondents may have local experience of a conservation strategy, such as supplementary feeding, which is not part of a national scheme).

\begin{tabular}{|c|c|c|c|c|c|c|c|c|c|c|c|}
\hline \multicolumn{2}{|c|}{ Conservation strategies } & \multicolumn{9}{|c|}{ Country } & \multirow[b]{2}{*}{ Total countries } \\
\hline Category & Strategy & BY & $\mathrm{CZ}$ & $\mathrm{DE}$ & ES & FI & FR & GB & IE & NL & \\
\hline \multirow[t]{2}{*}{ Protection } & Protected area & ○ & $\infty$ & 0 & - & 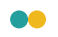 & & $\infty$ & ○ & $\odot$ & 8 \\
\hline & Species-specific protected area (SPA) & & 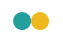 & 0 & ○ & & & $\bullet$ & $\bullet$ & 0 & 6 \\
\hline \multirow[t]{5}{*}{ Species management } & Nest protection (from direct or indirect persecution) & & $\bullet$ & $\infty$ & - & & & $\bullet$ & $\bullet$ & $\bullet$ & 6 \\
\hline & Supplementary feeding & & & & & & & - & ○ & $\bullet$ & 3 \\
\hline & Brood management & & & & - & & & - & & & 2 \\
\hline & Predator control (nest scale) & & & 0 & - & & - & 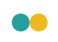 & & ○) & 5 \\
\hline & Predator control (landscape scale) & & & $\bullet$ & & ○) & & $\bullet$ & - & $\bullet$ & 5 \\
\hline \multirow[t]{4}{*}{ Habitat management } & Improvement of nesting habitat & & & $\bullet$ & & 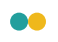 & & $\bullet$ & - & ๑ & 5 \\
\hline & Improvement of foraging habitat & - & & $\infty$ & & & & - & - & $\bullet$ & 5 \\
\hline & Improvement of linear features & & & & & - & & $\bullet$ & - & $\bullet$ & 4 \\
\hline & Improvement of grazing regimes & & & $\bullet$ & & & & - & - & $\infty$ & 4 \\
\hline \multirow[t]{3}{*}{ Policy and legislation } & Regulation of afforestation and forestry activities & & & - & & $\infty$ & & - & - & & 4 \\
\hline & Regulation of recreation & & & $\bullet$ & & & & ? & - & 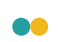 & 4 \\
\hline & Rodenticide use regulation & & & 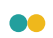 & & & & & & & 1 \\
\hline
\end{tabular}




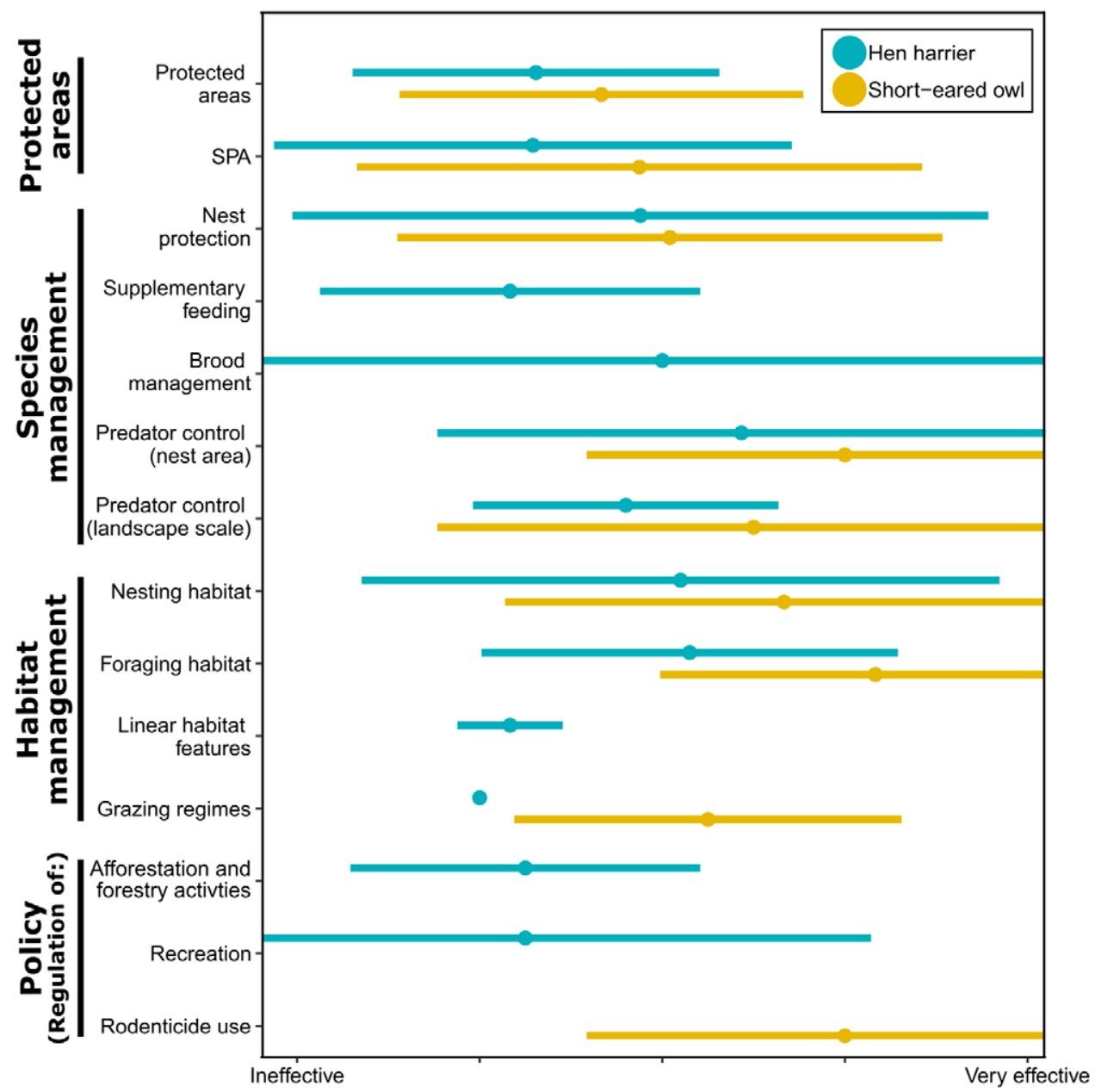

Figure 5. Perceived effectiveness of conservation strategies for breeding Hen Harrier and Shorteared Owl assessed by European experts through questionnaires $(n=23$ responses from nine countries for Hen Harrier; $n=12$ responses from six countries for Short-eared Owl). Dots indicate mean values for each conservation strategy across all countries, lines indicate standard deviation. See Table $\mathrm{S}_{4}$ for mean and standard deviation values.

indirect persecution), but can also modulate ecological factors (e.g. predation rates and prey availability can be affected by habitat loss, agricultural intensification or species introductions, Millon et al. 2002, Amar and Redpath 2005, Fraser et al. 2015). Many of these threats affecting Hen Harrier and Short-eared Owl populations are thus likely to be exacerbated in the coming decades under current predictions of climate and land use change (Rounsevell et al. 2006, European Environment Agency 2019). For example, increased frequency of extreme weather events can magnify fluctuations in prey populations, while predicted afforestation and agricultural intensification will lead to loss and deterioration of foraging and nesting habitats. These patterns highlight the urgent need for identification and implementation of effective conservation strategies. In this sense, the similarities in threat scores are suggestive of the potential for joint conservation actions to benefit Hen Harrier and Short-eared Owl populations, such as common strategies to reduce 
predation risk (through management of predator species and nesting habitat) or to increase prey availability (through improvement of foraging habitats).

While our findings underline broad similarities between conservation issues faced by Hen Harrier and Short-eared Owl, they also highlight regional differences. Indeed, some specific threats appear to be very important in some areas but not in others. Examples of these include direct persecution in the UK, afforestation in Ireland, agricultural intensification in the Netherlands, or accidental nest destruction by harvesting operations in farmland nesting habitats in France and Spain. Therefore, while European-wide strategies would prove effective for the conservation of both species, any such broad scale approaches should be combined with country-specific actions to address regional threats. Our findings also highlight how small populations are perceived to be vulnerable to a broader range of threats than larger populations. This reflects the increased importance of stochastic events for small populations (Melbourne and Hastings 2008). Thus, at a European scale, conservation efforts for both species should prioritise actions that address factors highlighted as important for larger populations (ecological and anthropogenic habitat change). At a national scale and for smaller populations, conservation actions must rely on region-specific studies to identify key threats and conservation recommendations for those areas. Although the analysis of perceived importance of threats in relation to number of breeding pairs provides useful insights, it is important to note that this assessment is limited by the number of responses obtained from some countries and by the number of pairs covered by each response. For instance, although France holds one of the largest European populations of Hen Harrier (5,300-8, ooo breeding pairs, European Environment Agency 2012), we only obtained a single response from this country covering 120 pairs. This may explain the apparent reduced importance of indirect persecution (including accidental nest destruction) in our analysis, despite its recognised importance for French Hen Harrier populations (Millon et al. 2002). Similarly, although direct persecution appeared to be important for large populations, this is partially influenced by the importance of shooting and intentional nest destruction for the UK populations, which had good coverage by the questionnaire responses (but see Figure $\mathrm{S}_{1}$ and Tables $\mathrm{S}_{2}$ and $\mathrm{S}_{3}$ for its importance in other areas).

Assessments of threats in areas not covered by our questionnaire are complicated in some countries where the species are abundant and not of conservation concern (Staneva and Burfield 2017) and therefore not the focus of research (e.g. Sweden, N. Kjellén pers. comm.). However, in other areas, there are overlaps between threats to both species similar to the patterns described here (A. V. Sharikov, A. Sokolov, S. Volkov pers. comm.). For example, in Russia, abandonment of agricultural lands (and subsequent succession and afforestation) along with intensification of agriculture is negatively affecting Hen Harrier and Short-eared Owl populations through habitat loss and reductions in prey availability (Volkov et al. 2009, Sharikov et al. 2019). In Iceland, Shorteared Owls are most affected by extreme weather events and habitat loss due to afforestation, with conservation efforts complicated by limited knowledge of the species' ecology and difficulties associated with monitoring (G. T. Hallgrimsson pers. comm.), similarly to patterns observed elsewhere in Europe.

There was more variation between expert perceptions of conservation strategy effectiveness than perceptions of importance of threats. This difference may be explained by higher region-specificity of conservation strategy effectiveness (i.e. a strategy effective in one region may be ineffective in another), or by lower consensus among European experts on the effectiveness of conservation strategies. Despite this, responses for both species were still broadly similar. Interestingly, the most effective conservation strategies according to responses were considered to be those relating to management of habitats(nesting and foraging) and species (nest protection and predator control). This suggests that effective conservation of Hen Harrier and Short-eared Owl populations should prioritise active management strategies rather than passive protection measures.

Protected areas were rated as having intermediate or low effectiveness, despite being the most common conservation strategy (Table 2), with surprisingly little difference between speciesspecific areas (Special Protection Areas) and other protected areas (national parks, reserves, etc.). These perceptions can be better understood in the context of the much-debated contribution of 
protected areas towards biodiversity conservation (Fuller et al. 2010, Geldmann et al. 2019). Protected areas are sometimes considered little more than 'paper parks', i.e. high-protection/ low-enforcement (Di Minin and Toivonen 2015, Coad et al. 2019), and research at a global scale suggests that the effectiveness of protected areas hinges on local resources and management (Leverington et al. 2010, Watson et al. 2014, Kuempel et al. 2018). Furthermore, while protected areas are shown to help conserve habitats, there is mixed evidence for their effectiveness at maintaining species populations (Geldmann et al. 2013). For Hen Harrier and Short-eared Owl European populations, this may be partially explained by the species' ecology. Migratory and dispersal movements by both species extend far beyond the size of most protected areas. In the case of Short-eared Owl, their reliance on small mammal population outbreaks that occur at irregular intervals over large spatial scales (Olsen et al. 2019) further emphasize the shortcomings of current protected areas that do not account for such spatial variations. Moreover, as ground-nesters, both species are highly vulnerable to predation as well as to nest destruction, both accidental (from mowing and harvesting activities) and intentional (see references in Bos et al. 2020). Therefore, proactive nest protection (e.g. predator control, nest protection or guarding) is often necessary to maintain breeding populations, even inside protected areas. In the context of the questionnaire responses, the fact that different types of protected areas are rated similarly could indicate deficiencies in designation of species-specific protected areas (i.e. location and size not matched to breeding and foraging ranges) or that management of these areas is not sufficiently adequate for the species' requirements. Another possible explanation for the perceived ineffectiveness of protected areas may be linked to the timing of designation - as many of the protected areas considered here would have been designated relatively recently under the Birds Directive. In these cases, much of the habitat loss would have already occurred and therefore the designation may have been successful in halting further habitat loss but not in restoring habitats, with the result that the populations of target species have not increased since designation. Our findings suggest that combining protected areas (currently seen as ineffective) with habitat and species management measures (perceived as most effective) can improve current conservation approaches. The implementation of targeted and region-specific habitat and species management measures would thus serve to enhance the performance of protected areas. The perceived low effectiveness of the most widely employed strategy (SPAs) also highlights the importance of continued assessment and monitoring of the effectiveness of protected areas in particular and of conservation strategies in general after implementation. In this context, establishing conservation objectives and monitoring programmes should be a requirement for the designation of protected areas.

Results on the effectiveness of proactive conservation strategies can help inform which ones may be implemented in combination with existing or future protected areas. Although nest protection was considered effective, other proactive management measures were considered ineffective (e.g. supplementary feeding and brood management for Hen Harrier). In some cases, ineffective strategies were also characterised by a lack of expert consensus underlined by large SD values, as in the case of brood management (the removal of eggs or chicks from a nest for rearing and release into other areas, a strategy mostly relevant to the UK at the time questionnaire respondents were contacted; Barkham 2019, St John et al. 2019). For Short-eared Owl, management of grazing regimes and regulation of rodenticide use through policy were also considered to be effective. The different perception of the relevance of these strategies compared to those for Hen Harrier relates to the ecological differences between both species, as Short-eared Owl diet is more strongly dominated by small mammals which are more likely to be affected by grazing regimes and rodenticides. In the case of rodenticide use, it is important to note that there is a gap in current knowledge on the rodenticide exposure of either species in Europe and that exposure may not necessarily be related to the importance of small mammals in the diet (Hughes et al. 2013, Lohr 2018).

Although questionnaire responses identified the conservation strategies perceived as most effective, different ecological aspects of European Hen Harrier and Short-eared Owl populations important for their conservation remain understudied. Knowledge gaps considered to be hindering effective conservation of both species were identified following discussions with delegates at the 
International Hen Harrier and Short-eared Owl meeting (Bos et al. 2020). Three key actions were defined to address knowledge gaps regarding European Hen Harrier populations: (i) an assessment and comparison of Hen Harrier breeding output across European countries (measured as number of fledglings per breeding attempt to account for failed nesting pairs); (ii) a pan-European tagging programme to improve current understanding of dispersal, juvenile mortality and low recruitment rates; (iii) research on male mortality by means of tagging studies to understand the skewed sex ratios (and high numbers of unpaired females) reported for several populations. Short-eared Owl conservation faces even greater challenges for research, as even basic aspects of the species' ecology are poorly understood. Difficulties stemming from the species' fluctuating population and range were identified as a major hurdle for research (e.g. year-to-year explosions and drops in breeding numbers in response to small mammal population cycles). Such difficulties and lack of knowledge on this species are reflected by our results, with just one third of questionnaire responses concerning Short-eared Owl. International collaboration can benefit both species, by collating information on methodologies and best practice for specific conservation strategies in place across their range that can be applied at a European scale or in combination with the protected areas approach.

Finally, this study serves to highlight the value of expert knowledge approaches in conservation (Martin et al. 2012). These can provide valuable insights when empirical data are lacking and represent a cost- and time-effective method to collate information on a broad range of topics which would otherwise require many separate ecological studies (e.g. assessment of 24 threats and 14 conservation strategies for two species across multiple countries). Furthermore, they serve to capture knowledge which may otherwise remain unpublished or inaccessible. This is especially relevant as new conservation strategies are trialled or amended for these species across Europe, e.g. results-based agri-environment schemes (Hen Harrier Project 2018), grouse moor licencing (Grouse Moor Management Review Group 2019), allowing for assessments of their effectiveness and providing a platform to disseminate and share knowledge with policy makers and the wider conservation and research communities. Expert knowledge consultations are not, however, without limitations. As an assessment of perceptions, such approaches can be subject to different forms of bias (e.g. under- or over-estimating the importance of threats), although these can be accounted for with appropriate study design (Martin et al. 2012, Drescher et al. 2013). Availability of experts across all study areas or topics can also limit the relevance or applicability of findings. This is exemplified in our study by the limited coverage of Nordic and eastern European countries (limiting the relevance of our findings in those areas), and by the reduced number of responses on Short-eared Owl compared to Hen Harrier (which reflect the lack of knowledge and difficulty in studying this species). Despite such considerations, and perhaps most importantly in our study, this approach encapsulates experts' willingness for knowledge-sharing and international collaboration that are necessary for the long-term conservation of these species, and represents an opportunity for continued growth in this direction (e.g. expanding knowledge sharing to areas poorly represented here, repeating the questionnaire in future once a wider network of experts is established).

\section{Implications for conservation}

Our work provides an overview of current knowledge on the conservation scenario for Hen Harrier and Short-eared Owl in Europe. The expert knowledge approach helps identify some important patterns for the conservation of both species. Firstly, it highlights the need for international collaboration on both research and conservation initiatives. Despite being studied as separate populations, Hen Harrier and Short-eared Owl from different European countries are ecologically connected (Mead 1973, Calladine et al. 2012, Klaassen et al. 2014, Murphy 2019, Schaub and Klaassen 2019) and are affected by many of the same threats. Identification of similarities between countries (see for example Figure 3 and Tables $\mathrm{S}_{2}$ and $\mathrm{S}_{3}$ ) can provide a first avenue for establishing international collaborations and knowledge-sharing on best practice to address conservation threats. Furthermore, the overlap of conservation threats described in this paper emphasises the potential value of multi-species conservation approaches. Effectiveness of conservation strategies can be dramatically increased if single actions are designed that can benefit multiple species. 
Secondly, the findings of this study underline specific shortcomings in current conservation approaches. The perceived ineffectiveness of passive conservation (protected areas) versus the effectiveness of active conservation (species and habitat management) provides an opportunity for improving current strategies. Protected areas, and in particular those designated for particular species, are perceived to be ineffective as stand-alone conservation strategies. Our findings suggest that designation of protected areas should be combined with species specific conservation strategies (e.g. species and habitat management measures) that benefit the species populations' (see Bos et al. 2020 for examples of species and habitat management strategies for Hen Harrier and Short-eared Owl). This study also highlights that a number of measures currently implemented to improve the conservation status of Hen Harrier and Short-eared Owl are perceived to be ineffective and therefore represent poor use of resources. This underscores the need to evaluate the performance of species-specific conservation measures to allow for adaptive management strategies. Determining the response of the target species to specific conservation measures (for example monitoring population size and/or breeding performance before, during and after the implementation of conservation measures) is essential to identify the effectiveness of such measures (e.g. in Ireland, five-yearly national Hen Harrier surveys have identified continued declines within SPAs, resulting in allocation of resources to yearly monitoring and habitat management in these areas; Ruddock et al. 2016, Hen Harrier Project 2018). Setting measurable Conservation Objectives or Favourable Reference Values as recommended under EU Birds and Habitats Directive (Bijlsma et al. 2018) allows the performance of conservation measures to be measured over time. Defining specific conservation objectives or targets (e.g. number of pairs in a population, prey abundance, cover of a specific type of habitat) which can be monitored on a regular basis, enables a flexible conservation approach that can adapt to ongoing changes (e.g. population size and trends, land use changes, development pressures).

Finally, this study indicates worrying trends in populations of Hen Harrier and Short-eared Owl across Europe. While this does not represent a comprehensive assessment of the status and trends of either species, it does confirm continued declines across large parts of their ranges. For Hen Harrier, these findings suggest that it may be necessary to consider the need for a pan-European species action plan (including country-specific strategies for regional threats), for countries to reassess the species' national status in light of their conservation status across Europe, and to re-assess the species' IUCN global conservation status (Bos et al. 2020). In the case of Short-eared Owl, the fluctuating nature of the population complicates status assessments. Indeed, the main issue raised by European experts on this species is our current lack of knowledge on its ecology and population trends. International initiatives would be a strong first step towards improving our understanding of a species with such a fluctuating breeding range. The long-term future of breeding populations of both species in Europe will depend on the development and implementation of collaborative international monitoring, research, and conservation strategies.

\section{Supplementary Material}

To view supplementary material for this article, please visit https://oi.org/10.1017/ So959270920000349

\section{Acknowledgements}

We thank all anonymous experts who replied to the pilot and final versions of the questionnaire. The International Hen Harrier and Short-eared Owl meeting on 20-22 March 2019 in the Netherlands was organised under the umbrella of the 'Wadvogels van Allure' project funded by Waddenfonds, the Dutch provinces North-Holland and Friesland, the Prins Bernard Cultuurfonds and the Bettie Wiegman Fonds. This study was funded by the Irish Department of Agriculture, Food \& the Marine, with additional funding provided by MKO Research. 


\section{References}

Amar, A. and Redpath, S. M. (2005) Habitat use by Hen Harriers Circus cyaneus on Orkney: implications of land-use change for this declining population. Ibis 147: 37-47.

Barkham, P. (2019) June 6. Hen harrier chicks to be reared in captivity to placate grouse moor owners. The Guardian. https://www. theguardian.com/environment/2019/jun/ o6/hen-harrier-chicks-to-be-reared-in-cap tivity-to-placate-grouse-moor-owners

Bierregaard, R. O., Kirwan, G. M., Boesman, P. and Marks, J. S. (2019) Cinereous Harrier (Circus cinereus). In J. Del Hoyo, A. Elliott, J. Sargatal, D. A. Christie and E. de Juana, eds. Handbook of the birds of the world alive. Barcelona: Lynx Edicions.

Bijlsma, R. J., Agrillo, E., Attorre, F., Boitani, L., Brunner, A., Evans, P., Foppen, R., Gubbay, S., Janssen, J. A. M., van Kleunen, A., Langhout, W., Noordhuis, R., Pacifici, M., Ramírez, I., Rondinini, C., van Roomen, M. and Winter, H. V. (2018) Defining and applying the concept of Favourable Reference Values for species and habitats under the EU Birds and Habitats Directives. Page 92. Technical report to the European Commission, Wageningen.

BirdLife International (2004) Birds in Europe: population estimates, trends and conservation status. Cambridge: BirdLife International.

BirdLife International (2019) IUCN Red List for birds. http://www.birdlife.org.

BirdLife International and HBW. (2018) Bird species distribution maps of the world. Version 2018.1. http://datazone.birdlife.org/ species/requestdis.

Bos, J., Schaub, T., Klaassen, R. and Kuiper, M., eds. (2020) Book of abstracts. International Hen Harrier and Short-eared Owl meeting 2019. Groningen, The Netherlands. https:// grauwekiekendief.nl/wp-content/uploads/ 2020/07/hh-seo-meeting-2019-book-ofabstracts.pdf.

Calladine, J., du Feu, C. and du Feu, R. (2012) Changing migration patterns of the Shorteared Owl Asio flammeus in Europe: an analysis of ringing recoveries. J. Ornithol. 153: 691-698.
Calladine, J., Garner, G., Wernham, C. and Buxton, N. (2010) Variation in the diurnal activity of breeding Short-eared Owls Asio flammeus: implications for their survey and monitoring. Bird Study 57: 89-99.

Coad, L., Watson, J. E., Geldmann, J., Burgess, N. D., Leverington, F., Hockings, M., Knights, K. and Marco, M. D. (2019) Widespread shortfalls in protected area resourcing undermine efforts to conserve biodiversity. Frontiers Ecol. Environ. 17: 259-264.

Del Hoyo, J., Collar, N. and Marks, J. S. (2019) Northern Harrier (Circus hudsonius). In J. Del Hoyo, A. Elliott, J. Sargatal, D. A. Christie and E. de Juana, eds. Handbook of the birds of the world alive. Barcelona: Lynx Edicions.

Di Minin, E. and Toivonen, T. (2015) Global protected area expansion: creating more than paper parks. BioScience 65: 637-638.

Doi, H. and Takahara, T. (2016) Global patterns of conservation research importance in different countries of the world. PeerJ 4 : e2173.

Drescher, M., Perera, A. H., Johnson, C. J., Buse, L. J., Drew, C. A. and Burgman, M. A. (2013) Toward rigorous use of expert knowledge in ecological research. Ecosphere 4: art83.

European Environment Agency (2012) Reporting under Article 12 of the Birds Directive (period 2008-2012). https://bd.eionet. europa.eu/activities/Reporting/Article_I2.

European Environment Agency (2019) Global and European temperature. Copenhagen: European Environment Agency.

Fraser, E. J., Lambin, X., McDonald, R. A. and Redpath, S. M. (2015) Stoat (Mustela erminea) on the Orkney Islands - assessing risks to native species. Stornoway: Scottish Natural Heritage. (Scottish Natural Heritage Commissioned Report No. 871).

Fuller, R. A., McDonald-Madden, E., Wilson, K. A., Carwardine, J., Grantham, H. S., Watson, J. E. M., Klein, C. J., Green, D. C. and Possingham, H. P. (2010) Replacing underperforming protected areas achieves better conservation outcomes. Nature 466 : $365-367$. 
Geldmann, J., Barnes, M., Coad, L., Craigie, I. D., Hockings, M. and Burgess, N. D. (2013) Effectiveness of terrestrial protected areas in reducing habitat loss and population declines. Biol. Conserv. 161: 230-238.

Geldmann, J., Manica, A., Burgess, N. D., Coad, L. and Balmford, A. (2019) A globallevel assessment of the effectiveness of protected areas at resisting anthropogenic pressures. Proc. Natl. Ac. Sci.116: 23209-23215.

Grouse Moor Management Review Group (2019) Grouse moor management review group report. Report to the Scottish Government. https://www.gov.scot/publica tions/grouse-moor-management-groupreport-scottish-government/

Hen Harrier Project (2018) Hen Harrier Project annual report. Galway, Ireland.

Henry, L. A. and Douhovnikoff, V. (2008) Environmental issues in Russia. Annu. Rev. Environ. Resour. 33: 437-46o.

Hughes, J., Sharp, E., Taylor, M. J., Melton, L. and Hartley, G. (2013) Monitoring agricultural rodenticide use and secondary exposure of raptors in Scotland. Ecotoxicology 22: $974-984$.

IUCN (2012a) IUCN Threats Classification Scheme version 3.2. https://nc.iucnredlist. org/redlist/content/attachment_files/dec_ 2012_guidance_threats_classification_ scheme.pdf.

IUCN (2012b) IUCN Conservation Actions Classification Scheme version 2.o. https:// nc.iucnredlist.org/redlist/content/attach ment_files/dec_2012_guidance_conserva tion_actions_in_place_classification_ scheme.pdf.

Klaassen, R., Schlaich, A. E., Bouten, W., Both, C. and Koks, B. J. (2014) First results of yearround tracking of Hen Harriers Circus cyaneus breeding in the agricultural landscape of East-Groningen. Limosa 87: 135-148.

Korpimaki, E. and Norrdahl, K. (I991) Numerical and functional responses of kestrels, short-eared owls, and long-eared owls to vole densities. Ecology 72: 814-826.

Kuempel, C. D., Adams, V. M., Possingham, H. P. and Bode, M. (2018) Bigger or better: the relative benefits of protected area network expansion and enforcement for the conservation of an exploited species. Conserv. Lett. I1: e12433.
Leverington, F., Costa, K. L., Pavese, H., Lisle, A. and Hockings, M. (2010) A global analysis of protected area management effectiveness. Environ. Manage. 46: 685-698.

Lohr, M. T. (2018) Anticoagulant rodenticide exposure in an Australian predatory bird increases with proximity to developed habitat. Sci. Total Environ. 643: 134-144.

Martin, T. G., Burgman, M. A., Fidler, F., Kuhnert, P. M., Low-Choy, S., McBride, M. and Mengersen, K. (2012) Eliciting expert knowledge in conservation science. Conserv. Biol. 26: 29-38.

Mead, C. J. (1973) Movements of British raptors. Bird Study 20: 259-286.

Melbourne, B. A. and Hastings, A. (2008) Extinction risk depends strongly on factors contributing to stochasticity. Nature 454: 100-103.

Mikkola, H. (2010) Owls of Europe. London, UK: Bloomsbury Publishing.

Millon, A., Bourrioux, J.-L., Riols, C. and Bretagnolle, V. (2002) Comparative breeding biology of Hen Harrier and Montagu's Harrier: an 8-year study in north-eastern France. Ibis 144: 94-105.

Murphy, S. (2019) Juvenile dispersal of Hen Harriers in the UK. P. II in J. Bos, T. Schaub, R. Klaassen and M. Kuiper, eds. (2020) Book of abstracts. International Hen Harrier and Short-eared Owl meeting 2019. Groningen, The Netherlands.

Olsen, P. D., Kirwan, G. M., Christie, D. A. and Marks, J. S. (2019) Short-eared Owl (Asio flammeus). In J. Del Hoyo, A. Elliott, J. Sargatal, D. A. Christie, and E. de Juana, eds. Handbook of the birds of the world alive. Barcelona: Lynx Edicions.

Orta, J., Kirwan, G. M., Boesman, P., Marks, J. S., Garcia, E. F. J. and Sharpe, C. J. (2019) Hen Harrier (Circus cyaneus). In J. Del Hoyo, A. Elliott, J. Sargatal, D. A. Christie and E. de Juana, eds. Handbook of the birds of the world alive. Barcelona: Lynx Edicions.

Rounsevell, M. D. A., Reginster, I., Araújo, M. B., Carter, T. R., Dendoncker, N., Ewert, F., House, J. I., Kankaanpää, S., Leemans, R., Metzger, M. J., Schmit, C., Smith, P. and Tuck, G. (2006) A coherent set of future land use change scenarios for Europe. Agric. Ecosyst. Environ. 114: 57-68. 
Ruddock, M., Mee, A., Lusby, J., Nagle, T. O'Neill, S. and O'Toole, L. (2016) The 2015 national survey of breeding Hen Harrier in Ireland. Dublin, Ireland: National Parks and Wildlife Service, Department of the Arts, Heritage and the Gaeltacht. (Irish Wildlife Manuals no. 93).

Salafsky, N., Salzer, D., Stattersfield, A. J., Hilton-Taylor, C., Neugarten, R., Butchart, S. H. M., Collen, B., Cox, N., Master, L. L., O'Connor, S. and Wilkie, D. (2008) A standard lexicon for biodiversity conservation: unified classifications of threats and actions. Conserv. Biol. 22: 897-911.

Schaub, T. and Klaassen, R. (2019) Movements and diet of Short-eared Owls in the Netherlands. P. 25 in J. Bos, T. Schaub, R. Klaassen and M. Kuiper, eds. (2020) Book of abstracts. International Hen Harrier and Short-eared Owl meeting 2019. Groningen, The Netherlands.

Sharikov, A. V., Volkov, S. V., Sviridova, T. V. and Buslakov, V. V. (2019) Cumulative effect of trophic and weather-climatic factors on the numbers dynamics of the voleeating birds of prey in their breeding habitats. Zoologicheskii Zhurnal 98: 203-213.

Smith, M. J., Weinberger, C., Bruna, E. M. and Allesina, S. (2014) The scientific impact of nations: Journal placement and citation performance. PLOS ONE 9: e109195.
St John, F. A. V., Steadman, J., Austen, G. and Redpath, S. M. (2019) Value diversity and conservation conflict: Lessons from the management of red grouse and hen harriers in England. People and Nature 1: 6-17.

Staneva, A. and I. Burfield. (2017) European birds of conservation concern: populations, trends and national responsibilities. Cambridge, UK: BirdLife International.

Village, A. (1987) Numbers, territory-size and turnover of Short-Eared Owls Asio flammeus in relation to vole abundance. Ornis Scand. 18: 198-204.

Volkov, S. V., Sviridova, T. V., Sharikov, A. V., Grinchenko, O. S. and Kolcov, D. B. (2009) Zakonomernosti biotopicheskogo i prostranstvennogo raspredeleniya bolotnoi sovy $\mathrm{v}$ agrolandshafte: vliyanie kachestvennykh kharakteristik mestoobitaniya. [Patterns of biotopic and spatial distribution of short-eared owl in an agricultural landscape: Influence of habitat quality]. Pp. 91-107 in S. V. Volkov, V. V. Morozov, and A. V. Sharikov, eds. Sovy Severnoi Evrazii: ekologiya, prostranstvennoe i biotopicheskoe raspredeleniya]. [Owls of Northern Eurasia: ecology, spatial and biotopic distribution]. Moscow: MPGU. (In Russian).

Watson, J. E. M., Dudley, N., Segan, D. B. and Hockings, M. (2014) The performance and potential of protected areas. Nature 515: $67-73$. 